University of Wollongong

Research Online

Faculty of Engineering and Information

Faculty of Engineering and Information

Sciences - Papers: Part A

Sciences

$1-1-2013$

\title{
Effect of microstructure and composition on hydrogen permeation in X70 pipeline steels
}

Ayesha J. Haq

University Of Wollongong, ayesha@uow.edu.au

K Muzaka

University of Wollongong, km646@uow.edu.au

D P. Dunne

University of Wollongong, druce@uow.edu.au

A Calka

University of Wollongong, acalka@uow.edu.au

E V. Pereloma

University of Wollongong, elenap@uow.edu.au

Follow this and additional works at: https://ro.uow.edu.au/eispapers

Part of the Engineering Commons, and the Science and Technology Studies Commons

Research Online is the open access institutional repository for the University of Wollongong. For further information contact the UOW Library: research-pubs@uow.edu.au 


\title{
Effect of microstructure and composition on hydrogen permeation in X70 pipeline steels
}

\author{
Abstract \\ The influence of microstructure and composition on permeation of hydrogen in 1.2 and $0.5 \mathrm{wt} . \% \mathrm{Mn}$ X70 \\ pipeline steels after different processing was investigated using an electrochemical permeation \\ technique. For $1.2 \mathrm{wt}$.\% Mn (standard Mn) steel, the microstructure of normalised transfer bar was coarse \\ equiaxed ferrite grains. This sample exhibited the highest diffusivity, followed by transfer bar, with a mixed \\ ferriteebainitic ferrite microstructure; and hot rolled strip, with fine elongated ferrite grains. The $0.5 \mathrm{wt} . \%$ \\ $\mathrm{Mn}$ (medium $\mathrm{Mn}$ ) strip displayed lower diffusivity than the $1.2 \mathrm{wt} . \% \mathrm{Mn}$ strip, due to hydrogen trapping by \\ finer ferrite grains and a higher density of carbonitride precipitates. Moreover, the medium Mn strip \\ exhibited a uniform microstructure and consequently similar diffusion coefficients for the edge and \\ centreline regions, whereas the finer grains of the edge region of the standard Mn strip resulted in a lower \\ diffusivity than the centreline region. Copyright @ 2012 , Hydrogen Energy Publications, LLC.

\section{Keywords} \\ $x 70$, permeation, steels, hydrogen, pipeline, composition, microstructure, effect \\ Disciplines \\ Engineering | Science and Technology Studies

\section{Publication Details} \\ Haq, A. J., Muzaka, K., Dunne, D. P., Calka, A. \& Pereloma, E. V. (2013). Effect of microstructure and \\ composition on hydrogen permeation in X70 pipeline steels. International Journal of Hydrogen Energy, 38 \\ (5), 2544-2556.
}


Revised Manuscript

Click here to view linked References

\title{
Effect of Microstructure and Composition on Hydrogen Permeation in X70 Pipeline Steels
}

\author{
Ayesha J. Haq, K. Muzaka, D.P. Dunne, A. Calka, E.V. Pereloma
}

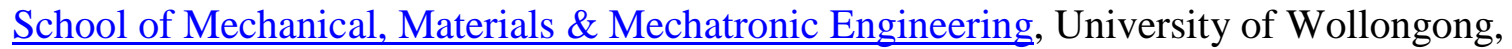

Wollongong NSW 2522 Australia 


\section{Abstract}

The influence of microstructure and composition on permeation of hydrogen in 1.2 and $0.5 \mathrm{wt} . \%$ Mn X70 pipeline steels after different processing was investigated using an electrochemical permeation technique.

For 1.2 wt.\% Mn (standard Mn) steel, the microstructure of normalised transfer bar was coarse equiaxed ferrite grains. This sample exhibited the highest diffusivity, followed by transfer bar, with a mixed ferrite - bainitic ferrite microstructure; and hot rolled strip, with fine elongated ferrite grains.

The 0.5 wt. $\%$ Mn (medium Mn) strip displayed lower diffusivity than the $1.2 \mathrm{wt} . \%$ Mn strip, due to hydrogen trapping by finer ferrite grains and a higher density of carbonitride precipitates. Moreover, the medium Mn strip exhibited a uniform microstructure and consequently similar diffusion coefficients for the edge and centreline regions, whereas the finer grains of the edge region of the standard Mn strip resulted in a lower diffusivity than the centreline region.

Keywords: pipeline steel, permeability, diffusion, traps, microstructure, grain size, inclusions, precipitates, dislocations 


\section{Effect of Microstructure and Composition on Hydrogen Permeation in X70 Pipeline Steels}

\section{Introduction}

X70 pipeline steels are widely used to transport petroleum and natural gas. The service life of pipeline steels is affected not only by the fluid or gas which they transfer, but also by the environmental conditions under which they operate. One of the main reasons for the degradation in mechanical properties of steels is the exposure to hydrogen. For example, on exposure to a sour gas environment, the steel surface corrodes and produces hydrogen at the surface. This hydrogen can be absorbed in the steel and can then start diffusing to regions of stress concentration, impairing ductility and promoting brittle behavior (hydrogen embrittlement). Since the transport of hydrogen to a critical region is dependent on diffusion, hydrogen transport is an important step in the process of embrittlement. Therefore, it is important to determine the diffusion rate of hydrogen in pipeline steels in order to predict their mechanical properties and inservice behaviour.

The diffusion of hydrogen in steels is affected by the microstructure of the steel: the phase or phases present, grain boundaries, grain shapes, vacancies and dislocations, interfaces with nonmetallic inclusions, precipitate particles and voids [1-3]. These features can reduce the mobility of hydrogen by acting as traps. Traps are generally classified as reversible and irreversible, based on the strength of their bond with hydrogen atoms. Grain boundaries and dislocations and microvoids that have low trap binding energies are considered to be reversible traps. Of these, grain boundaries can either increase the diffusion of hydrogen by providing faster paths for diffusion [4-6] or reduce the mobility of hydrogen by acting as reversible hydrogen trapping sites at nodes and junction points [7-10]. As a result of these two contradictory effects, Ichimura et al. [11] suggested that the hydrogen diffusion coefficient will be a maximum at an optimum grain size and Yazdipour et al. [12] confirmed this by modeling as well as permeation experiments.

Irreversible traps, on the other hand are those that trap hydrogen permanently at temperatures close to ambient and are associated with high binding energies. These traps include non-metallic inclusions and precipitates. Several types of inclusions have been identified in pipeline steels 
such as $\mathrm{Al}_{2} \mathrm{O}_{3}$, complex $(\mathrm{Fe}, \mathrm{Mn}) \mathrm{S}$ or double oxide $\mathrm{FeO} . \mathrm{Al}_{2} \mathrm{O}_{3}$ inclusions, mixed compounds containing Al-Mg-Ca-O, Si-ferric carbide and MnS [13-14]. Lee and Lee [15] considered MnS inclusions to be strong irreversible trapping sites for hydrogen. However, Garet et al. [16] reported that $\mathrm{MnS}$ particles act as reversible trapping sites since they have moderate binding energies. They also reported that the trapping efficiency increased with sulphur content. In addition to inclusions, precipitates of $\mathrm{Ti}, \mathrm{Nb}$ and $\mathrm{V}$ such as $\mathrm{TiC}, \mathrm{TiN}, \mathrm{NbC}, \mathrm{VC}$, complex $\mathrm{Ti}, \mathrm{Nb}(\mathrm{C}, \mathrm{N}), \mathrm{Ti}_{4} \mathrm{C}_{2} \mathrm{~S}_{2}$ etc., are all considered to be irreversible traps [2, 17-24].

In the past few decades, several investigations have dealt with the influence of various parameters on diffusion in pipeline steels [14, 25-35]. Table 1 summarises diffusion coefficients and other parameters obtained, for pipeline steels, by different authors along with other related information such as the solutions employed, exit side coating and method used for calculating the diffusion coefficient. Andenna and Torella [25] studied the effect of stress on the permeability of X65 pipeline steels and reported that there was no effect for the base material with a ferrite-pearlite microstructure, whereas the hydrogen diffusivity and flux for quenched material comprising a bainitic microstructure with martensite-austenite islands decreases with increasing level of stress. Park et al. [31] investigated the effect of microstructure on the trapping efficiency of X65 pipeline steel and reported that the efficiency of trapping increases in the order: degenerated pearlite, bainite and acicular ferrite. The diffusivity of hydrogen and density of traps in X70 and X100 steels were estimated by Dong et al. [27-28]; and for X80 by Xue et al. [14]. Kim et al. [29] investigated the effect of environmental factors such as $\mathrm{H}_{2} \mathrm{~S}$ partial pressures and $\mathrm{pH}$ values on the permeation of hydrogen in high strength low alloy (HSLA) steels and found that reversible trapping was affected by $\mathrm{H}_{2} \mathrm{~S}$ rather than $\mathrm{pH}$. The effect of precipitates was investigated by Koh et al. [30] who reported that diffusion of hydrogen was related to the volume fraction of carbonitride precipitates rather than the ferrite microstructure. Huang et al. [13] studied the ability of microstructures and inclusions to trap hydrogen in three different X120 steels having similar amounts of $\mathrm{Ti}, \mathrm{Nb}(\mathrm{C}, \mathrm{N})$ precipitates and found that irreversible hydrogen trapping efficiency increases with the volume fraction of non-metallic inclusions such as $\mathrm{Al}_{2} \mathrm{O}_{3}$ and MnS. Skjellerudsveen et al. [35] studied the diffusion of hydrogen in X70 pipeline steel, simulated coarse grain heat affected zone (CGHAZ) and weld metal and found that the diffusion coefficient decreased in the order: weld metal, X70 steel and HAZ. Further, the change in diffusion coefficient with temperature was similar for the three materials. 
Since pipeline steels are produced by thermo-mechanically controlled processes (TMCP), a range of microstructures can result depending on the actual processing conditions. Consequently, the microstructure, grain size, volume fraction of inclusions and precipitates, and dislocation density can vary within a particular strength grade. Moreover, segregation of various elements can occur (depending on the partitioning tendency of each element) and inclusions can be concentrated in the slab centre, which solidifies last. Therefore, alloying elements and inclusions tend to be concentrated in the centreline region of transfer bar (TB) and in the hot rolled strip. It also follows that the chemical composition and microstructure of the edge differs from that in the centreline region. Moreover, the difference in the cooling rates of the edge and centreline can also introduce differences in grain size and dislocation density. To minimise the effects of segregation, the trend in recent years has been to shift to lower Mn levels [36].

Therefore, the aim of this study was to investigate the effect of microstructure and composition on hydrogen permeation in X70 pipeline steels. Permeation studies were performed on two pipeline steels having different compositions, namely standard X70 (1.2\% Mn) and medium X70 $(0.5 \% \mathrm{Mn})$. Samples were investigated from the transfer bar and hot rolled strip stages of production, and from different regions (centreline and edge). The diffusion coefficients for the different samples were estimated and the observed permeation transients were correlated with the microstructural features present in the steel specimens.

\section{Experimental}

\subsection{Materials and processing}

Standard X70 and medium Mn X70 grade pipeline steels were used in this investigation. The chemical compositions of the steels are listed in Table 2. Samples of size $40 \mathrm{~mm}$ x $40 \mathrm{~mm}$ and thickness slightly greater than $1 \mathrm{~mm}$ were obtained by wire cutting parallel to the rolling plane of the material as shown in Figure 1. Samples from the edge and centreline regions were taken from the TB of standard X70 steel and hot rolled strips of both standard and medium Mn X70 grades produced by BlueScope Steel Ltd. To eliminate the effect of residual strain and to obtain a normalised structure with equiaxed grains, samples from the edge region of TB were normalised in an argon atmosphere at $950^{\circ} \mathrm{C}$ for 20 minutes. The notation used for the samples investigated is given in Table 3. 


\subsection{Microstructural investigation}

After the completion of permeability tests, the cross-sections of the samples were cut from the region exposed to the electrolyte and prepared for optical metallography using the standard procedures. The samples were etched with $2 \%$ Nital solution and the microstructures were characterized both by optical microscopy and scanning electron microscopy (SEM) using a JEOL JSM 6490LV SEM at an excitation voltage of $20 \mathrm{kV}$. Since the transport of hydrogen was in the normal direction, the grain size, defined in terms of the mean free path in ferrite in the normal direction, was measured by the linear intercept technique. The hardness of the samples was determined using an INDENTEC Vickers hardness machine at a load of $10 \mathrm{~kg}$.

\subsection{Electrochemical hydrogen permeation test}

Hydrogen permeability measurements were performed by the electrochemical technique developed by Devanathan and Stachurski [37]. A modified dual cell made of two polycarbonate cells was employed. The specimen was held tightly between the two cells by using rubber gaskets in such a way that the entire system remained leak-tight and the solutions on either side of the specimen did not mix. The side of the membrane, at which hydrogen was to be generated, was maintained at a cathodic potential, whereas an anodic potential was applied on the detection side of the membrane. The equipment used for applying the required potentials was the Hyperm Mod HM 403.

The permeability tests were carried out at room temperature. The room temperature was in the range $21-23{ }^{\circ} \mathrm{C}$, as measured with a thermometer. Both surfaces of the specimen were abraded with 500 grit silicon carbide paper and cleaned with methanol. After preparation the final thickness of the sample was measured and recorded (the average of ten measurements was calculated). No Pd coating was applied at the exit side of the samples. The cleaned sample was placed in between the two cells and sealed by tightening the bolts. A circular area of $2.84 \mathrm{~cm}^{2}$ was exposed to the electrolyte. A platinum electrode was placed in the anodic cell and a stainless steel electrode in the cathodic cell and the steel specimen formed the working electrode in both cells. These electrodes were then connected to the terminals of the Hyperm unit. The anodic side or the detection cell was filled with $0.1 \mathrm{~N} \mathrm{NaOH}$ solution, and polarization was started. A background current was observed in the amperometer. With time the background current 
decreased. When this current decreased to a value below $3 \mu \mathrm{A}$, it was compensated by means of the zero shift using a null potentiostat. In effect, the background current was set to zero. Then the cathodic cell was filled with a solution containing $0.1 \mathrm{~N} \mathrm{NaOH}$ and a promoter, $\mathrm{Na}_{2} \mathrm{~S} .9 \mathrm{H}_{2} \mathrm{O}$ in order to accelerate the entry of hydrogen into the steel specimen. Alkaline solution was used for the permeation tests in order to reduce the interaction of sulphide inclusions with the electrolyte at the steel surface [38]. Initially, concentrations of 1,10 , and $100 \mathrm{~g} / \mathrm{L}$ of $\mathrm{Na}_{2} \mathrm{~S}_{2} 9 \mathrm{H}_{2} \mathrm{O}$ were used to study the effect of promoter concentration. The data indicated that an increase in the concentration of the promoter increased the steady state current density as well as the permeation rate, i.e., the time taken to reach steady state permeation was reduced. The steady state permeation current observed for $1 \mathrm{~g} / \mathrm{L}$ of $\mathrm{Na}_{2} \mathrm{~S} .9 \mathrm{H}_{2} \mathrm{O}$ was very low, close to the lower range of the measuring instrument. On the other hand, a higher concentration of promoter, i.e., $100 \mathrm{~g} / \mathrm{L}$, led to significant specimen corrosion. Therefore $10 \mathrm{~g} / \mathrm{L}$ of promoter was selected for all the experiments. The solutions were prepared from analar grade chemicals and milli Q water. Hydrogen entry into the steel was then facilitated by applying a constant cathodic current of 10 $\mathrm{mA}$ which gave a current density of $3.52 \mathrm{~mA} / \mathrm{cm}^{2}$. Hydrogen permeated through the specimen to the anodic side where it was instantaneously oxidised giving rise to an equivalent current in the exit cell which is a direct measure of the output flux of hydrogen. The Hyperm unit was connected to a computer through a data logger to record continuous current measurements throughout the experiment with data logging every 10 seconds.

After the application of the cathodic current on the entry side, the permeation current was initially zero for a period of time, after which it increased till it reached a steady state value. This is referred to as the rise transient. After reaching steady state, the entry side charging current was interrupted and the sample was allowed to outgas completely. The current then started decreasing and reached a low value after a period of time, giving rise to the decay transient. A second transient was then obtained by starting the current in the entry side again. Triplicate tests were conducted for each sample.

\subsection{Analysis of permeation transients}


The permeation transients were expressed in normalised units i.e., in terms of normalised flux and dimensionless time $[19,39]$. The flux was normalised with respect to the steady state value and the dimensionless time was obtained by using the equation,

$\tau=\mathrm{D}_{\mathrm{L}} \mathrm{t} / \mathrm{L}^{2}$

where, $\mathrm{D}_{\mathrm{L}}$ is the coefficient of diffusion of hydrogen in pure ferrite and was taken as $7.2 \times 10^{-9} \mathrm{~m}^{2} / \mathrm{s}$ at room temperature [39-40], $\mathrm{t}$ is the time in seconds and $\mathrm{L}$ is the thickness of the specimen in meters.

As mentioned earlier, the permeation current density observed at the exit side is a direct measure of the output flux of hydrogen. From the steady state permeation current density, $i_{p}^{\infty}$ the hydrogen permeation flux or permeability, $J_{\infty}$, is calculated using the equation:

$J_{\infty} L=i_{p}^{\infty} / Z F$

where, $\mathrm{Z}$ is the number of electrons transferred and $\mathrm{F}$ is the Faraday constant $\left(96,487 \mathrm{C} \mathrm{mol}^{-1}\right)$. The diffusion coefficients can be calculated from the permeation transients using a variety of methods as given below.

Using the breakthrough time $t_{b}$ :

$D_{t b}=L^{2} / 15.3 t_{b}$

and in terms of time lag $t_{l}$ :

$D_{T}=L^{2} / 6 t_{l}$

where, $D_{t b}$ is the diffusion coefficient calculated from breakthrough time and $D_{T}$ is the diffusion coefficient calculated from time lag. The breakthrough time is obtained from the intersection of the tangent at the inflection point of the permeation rate-time curve with the initial permeation 
level and the time lag is obtained from the time taken for permeation rate to reach 0.63 times the steady state value.

The diffusion coefficient can also be calculated from the rising transient using a plot of $\ln \left(\left(i_{p}-i_{p}^{\infty}\right) / i_{p}^{\infty}\right)$ against $t$ where, $i_{p}$ is the measured permeation current at time $\mathrm{t}$ and $i_{p}^{\infty}$ is the steady state permeation rate. This plot has a slope of $1 / t_{0}$, where, $t_{0}=L^{2} / \pi^{2} D$. Therefore,

$D=L^{2} / \pi^{2} t_{0}$

Another means of calculating the diffusion coefficient is based on the decay transient and

employs a plot of $\ln \left(i_{p} / i_{p}^{\infty}\right)$ against $t$. Again this plot has a slope of $1 / t_{0}$ from which $\mathrm{D}$ can be calculated using equation (9).

The apparent hydrogen solubility $\mathrm{C}_{\text {app }}\left(\mathrm{mol} \mathrm{H} / \mathrm{m}^{3}\right)$ can be determined by,

$\mathrm{C}_{\mathrm{app}}=J_{\infty} L / \mathrm{D}$

The trap density was calculated using the equation given by Dong et al. [28]

$$
N_{T}=N_{L}\left(\frac{D_{L}}{D}-1\right) e^{-\frac{E_{b}}{R T}}
$$

where $\mathrm{N}_{T}$ is the number of hydrogen trapping sites per unit volume $\left(\mathrm{m}^{-3}\right), \mathrm{N}_{\mathrm{L}}$ is the density of the interstitial sites in the steel and $E_{b}$ the hydrogen trap binding energy. The values of $N_{L}$, and $E_{b}$ were taken as $7.52 \times 10^{28} \mathrm{~m}^{-3}$ and $0.3 \mathrm{eV}$ respectively [28]. The trap density in this study was calculated using the diffusion coefficient calculated from the lag time of the first transient.

\section{Results}

\subsection{Microstructural characterization}

Figures 2 and 3 show typical microstructures of the different samples investigated. The samples taken from the edge and centreline regions of the standard and medium $\mathrm{Mn}$ strips basically revealed slightly elongated grains of ferrite-pearlite. For the standard $\mathrm{Mn}$ alloy, the edge microstructure (SME) and the centreline microstructure (SMC) are shown in Figures 2 (a), (b); 
and those for the medium Mn alloy MME and MMC are shown in Figures 2 (c) and (d). The optical image taken from the centreline region of the standard Mn strip (Figure 2 (b)) indicates that the ferrite grains are more uniform and generally coarser than those in the edge region (Figure 2 (a)), which is consistent with the slower cooling rate experienced by the centreline region during the hot rolling process, compared to the edge. A closer examination of the microstructures indicated that the grain sizes of edge and centreline regions of the standard Mn strip were characterized by a bimodal distribution. The edge region exhibited a larger volume fraction of fine grains with some larger grains which were approximately 5 times the average size of the finer grains. In contrast, the centreline region consisted of a smaller volume fraction of fine grains and a larger fraction of coarse grains that were about 3 times the average size of the fine grains. Furthermore, the centreline samples also exhibited regions with a banded ferrite-pearlite microstructure. The difference in average grain size is also evident from Table 3 which lists the grain size in terms of mean free path in the ferrite phase as well as the hardness of the various samples. The edge (Figure 2 (c)) and centreline regions (Figure 2 (d)) of the medium Mn strip, on the other hand, exhibited a more uniform microstructure with very similar mean grain sizes. This observation is quantified in Table 3. Moreover, no banding of the ferrite and pearlite was evident in the centreline region of the medium Mn strip.

The microstructure of the edge region of transfer bar (TBE) exhibited a banded structure comprising alternate bands of bainitic ferrite, labelled 1, and polygonal and/or quasi- polygonal ferrite, labelled 2 (Figure 3). A magnified image of TBE is shown in Figure 3 (b). The centreline region of the transfer bar (Figure 3 (c)) exhibited a microstructure of coarser ferrite plates and some quasi-polygonal ferrite which had formed from coarse grained austenite at a relatively slow cooling rate. This coarse lath ferrite structure is often described as granular bainite [41]. The microstructure of the normalised transfer bar edge sample is shown in Figure 3 (d). The microstructure consists of equiaxed ferrite-pearlite grains.

It is also clear from Table 3 that samples taken from the edge of the standard Mn strip exhibited a higher hardness than the samples taken from the centreline regions, whereas the medium $\mathrm{Mn}$ samples showed uniform hardness values. These values correlate well with the grain sizes of the samples. The transfer bar gave the unexpected result that the edge region was softer $(170 \pm 6$ $\mathrm{HV})$ than the core $(189 \pm 3 \mathrm{HV})$. The thickness of the transfer bar ensures a slower near-surface 
cooling rate than for hot rolled strip, thereby accounting for the lower hardness of TBE. The higher than expected core hardness could be due to Mn segregation that lowered the transformation temperature and increased strengthening by solute Mn [42].

\subsection{Permeation transients}

Figure 4 (a) is the complete permeation curve for a typical X70 specimen which includes the first transient, the decay and the second transient. In Figure 4(b) both the first and second transients are superimposed. The following observations can be made from these plots:

1. The first transient current increased rapidly, reached a maximum and remained steady for a short duration of time $(<10$ minutes for the NTB samples and about 30-40 minutes for the other samples). The current then decreased continuously even when the sample was still cathodically polarised.

2. Although the start of the second transient (the breakthrough time) appeared to be shorter, the rise in permeation current was not as rapid (Figure 4 (b)) i.e., the time taken to reach steady state was longer. Moreover, it did not reach the same permeation current as the first steady state value, which indicates that the permeation flux during the second transient is smaller than that observed in the first transient.

These results are similar to those of Manolatos et al. [43] for a pure iron specimen using $0.1 \mathrm{~N}$ $\mathrm{NaOH}$ in both cells. They attributed these observations to a passive oxide layer that forms on the exit side of the specimen in the absence of Pd coating when an anodic potential is applied. According to the authors, the passive layer formed on the exit side acts as a barrier to hydrogen evolution and does not allow the hydrogen concentration on the exit side to stabilise. This prevents the attainment of stationary conditions and consequently affects the steady state permeation flux. This trend of the permeation transient decreasing with time was also observed by Beck et al. [44], Amiot et al. [45] and Iino et al. [38]. Beck et al. [44] attributed it to void nucleation at an aggregate of dislocations and Amiot et al. [45] attributed it to the hydrogen flux loss through the breakage of surface blisters. However, similar to the present results for all samples, Iino et al. [38] did not observe any blisters. Bruzzoni et al. [46] also showed that, in the 
absence of Pd coating on the exit side, an oxide layer is formed, which reduces the permeation flux and also increases the time taken to reach steady state. Moreover, the entry side corrodes during the decay since no current is being applied. This alters the conditions at the hydrogen entry surface and could result in a lower or delayed hydrogen uptake during the second transient.

Skjellerudsveen et al. [35] did not observe any significant variation in the permeation curves of the first, second and third transients for X70 steel, coated with Pd on the exit side, at room temperature. The values of steady state current densities were also similar for the three transients. They also applied a positive potential to both sides during decay, contrary to the procedure used in the current investigation.

Our results are in agreement with the conclusions of Manolatos et al. [43] and Bruzzoni et al. [46] that, in the absence of Pd coating, the progressive formation of an oxide layer on the exit side does not allow a steady state permeation current to be maintained for a prolonged period during the permeation test, despite the cathodic polarisation of the sample. Hence the permeation current decreases after a relatively short steady state period during the first permeation cycle, as shown in Figure 4 (a). As a consequence of the film on the exit surface, the second permeation cycle shows a lower peak permeation current, Figures 4 (a) and (b), before the permeation current starts to fall as the barrier effect of the film increases.

The steady state permeation, in this study, did last for a short period of time, unlike the observations by Manolatos et al. [43], and made it possible to determine normalised permeation fluxes for carrying out comparisons. Permeation transients obtained for different samples investigated were similar to those shown in Figure 4 (a). The most reliable comparative data come from the first transient curve up to the time range of the steady state permeation current, because the influence of oxide film formation over this time period remains relatively low. Accordingly, the curves comparing the permeation characteristics of the samples tested, shown in Figures 6 (a) to (g), are for the first transient up to the steady state period.

\subsection{Diffusion coefficients}

Table 4 compares the diffusion coefficients calculated for the $1^{\text {st }}$ and $2^{\text {nd }}$ transients using the measured breakthrough times and lag times, and also from the rising first transient and decay 
transient for the different samples investigated in this study. There is a spread in the values of the diffusion coefficients obtained from the first transient due to the different calculation methods, as reported also by Turnbull et al. [39] and Charbonnier et al. [47]. The diffusion coefficients calculated from breakthrough times are the largest, whereas the diffusion coefficients calculated from lag times and rising first transients are quite similar and lower than the values calculated from the breakthrough times. Values calculated from the decay transient are significantly lower, consistent with the significantly longer times taken for the decay of hydrogen. Garet et al. [16] and Scoppio and Barteri [33] have also observed lower diffusion coefficients from the degassing transient and attributed this to hydrogen exchanges between reversible traps in ferritic steels which result in slow degassing when the hydrogen supply progressively decreases. Scoppio and Barteri [33] therefore suggest that the phenomena occurring during degassing are complex and hence the parameters estimated from degassing are less significant compared to the values determined from hydrogen uptake.

The shorter breakthrough time for the second transient, correlates with the consistently higher diffusion coefficient (1.11 to 1.79 times higher) than that for the first transient (Table 4). Table 4 also indicates that there are only minor differences in the diffusion coefficients calculated from the breakthrough time for the first transient for the different samples tested. The medium Mn edge sample exhibited the lowest diffusivity $\left(1.88 \times 10^{-10} \mathrm{~m}^{2} / \mathrm{s}\right)$ and the normalised transfer bar showed the highest diffusivity $\left(5.66 \times 10^{-10} \mathrm{~m}^{2} / \mathrm{s}\right)$. For the standard Mn strip, the samples taken from the edge of the strip gave a lower diffusion coefficient than the centreline region, whereas the difference between the edge and centreline regions was insignificant for the medium Mn strip.

The various estimates of diffusivity (excluding $\mathrm{D}_{\text {to }}$ decay) were in reasonable agreement for a given sample. Further, the trend in diffusivity values for the seven samples examined was similar for each of the six different calculation methods. For example, the average diffusivity for SMC was $2.63 \times 10^{-10} \mathrm{~m}^{2} / \mathrm{s}$ with a standard deviation of 0.71 .

Variation in hardness and diffusion coefficient with mean free path has been plotted in Figure 5 for the standard Mn strip edge, strip centreline and normalized transfer bar, which all had similar ferrite-pearlite microstructures. A linear correlation is evident between hardness and mean free path and also the diffusivity and mean free path. Consistent with literature, the hardness increases as the grain size (the mean free path in ferrite) decreases. In contrast, the diffusivity increases as 
the mean free path increases. These observations agree with an earlier study [12] which showed that the diffusion coefficient decreases with decreasing grain size for grains smaller than $45 \mu \mathrm{m}$.

\subsection{Trap densities and apparent hydrogen solubility}

The computed values of the density of traps, flux, permeability and the subsurface concentration

of hydrogen atoms are given in Table 5. The calculated trap densities varied from $1.3-3.1 \times 10^{18}$ $\mathrm{m}^{-3}$ for the different samples, being lowest for NTB samples and highest for the MME and MMC samples. This trend is consistent with the measured diffusion coefficients since the trap densities are inversely proportional to the diffusion coefficients. Furthermore, there was no difference in the trap densities of the edge and centreline regions for the medium Mn strip.

The apparent hydrogen solubility is also inversely related to the diffusion coefficient. Therefore, there were only minor differences in the apparent hydrogen solubility of the samples investigated.

\section{Discussion}

\subsection{Comparison of the estimated permeation parameters with literature}

In addition to the microstructure and composition of the steel, the diffusion of hydrogen can be influenced by other experimental factors including the solution used for permeability testing, the concentration of promoter (if any), the method used to calculate the diffusion coefficient and the presence or absence of Pd or an other coating on the exit side of the sample. Serna et al. [34] have also pointed out that the diffusion coefficient can depend on the charging conditions. Therefore, although several researchers have studied the diffusion of hydrogen in micro-alloyed pipeline steels, it is not easy to compare the diffusion coefficients. This is also evident from Table 1 which shows that the diffusion coefficients obtained by different researchers vary significantly.

Tables 1 and 4 show that the values of diffusion coefficient obtained in this study are an order of magnitude higher than those reported by Dong et al. [27] and Skjellerudsveen et al. [35] for X70 steel. The former researchers used an acidic solution of $\mathrm{H}_{2} \mathrm{SO}_{4}$ with $250 \mathrm{mg} / \mathrm{L} \mathrm{As}_{2} \mathrm{O}_{3}$ and the latter $0.1 \mathrm{~N} \mathrm{NaOH}$ without any promoter. Furthermore, the exit side was coated with $\mathrm{Pd}$ by Skjellerudsveen et al. [35] and Ni by Dong et al. [27]. The reported microstructures were also different. 
On the other hand, the results obtained from the present study are comparable to those reported by Park et al. [31], despite their use of NACE solution for the entry side and Pd coating on the exit side. Diffusion coefficients of $2.3-3 \times 10^{-10} \mathrm{~m}^{2} / \mathrm{s}$ were calculated, in the present study, from breakthrough times of the first transient for the standard X70 strip comprising a ferrite-pearlite structure. These results are about 3 times lower than the values of $9.27-9.38 \times 10^{-10} \mathrm{~m}^{2} / \mathrm{s}$ obtained by Park et al. [31] for ferrite-degenerated pearlite structures in X65 steel. However, a diffusion coefficient of $3.7 \times 10^{-10} \mathrm{~m}^{2} / \mathrm{s}$ obtained for the ferrite - bainitic ferrite structure (TBE) in this study is close to the value of $4.05 \times 10^{-10} \mathrm{~m}^{2} / \mathrm{s}$ reported by Park et al. [31] for their A2 steel with a similar microstructure. The present results are also comparable to the values reported by Koh et al. [30] for pipeline steels having ferrite-pearlite microstructures.

Although the diffusion coefficients are of the same order of magnitude, the values of permeability and subsurface concentration of hydrogen observed in this study are significantly lower that those reported by Park et al. [31]. This is possibly related to the different solutions used for the entry side as well as the presence of Pd coating in the case of Park et al. [31] which allows full oxidation of the hydrogen arriving at the exit side and gives rise to a higher permeation flux.

\subsection{Comparisons of the different samples studied}

As discussed earlier, the diffusion coefficients of the different samples tested here were of the same order of magnitude, with only some minor differences. However, if the first permeation transients of the different sets of sample conditions are plotted on the same graph, as shown in Figures 6 (a) to (g), clear differences in the permeation behaviour of the samples are more noticeable. These differences are discussed below.

\subsubsection{Comparison of standard Mn strip edge and centreline}

Figure 6 (a) shows the first permeation transient of the SME and SMC samples. It is apparent from this figure that not only is the breakthrough time longer in the edge samples, but the transient is less steep, which implies that it contains a higher density of traps which reduce the mobility of hydrogen. Therefore it takes a longer time to fill the traps and consequently reach a steady state permeation current. 
During continuous casting, Mn has a strong tendency to segregate to the centreline region of the slab. Escobar et al. [48] have demonstrated by etching with LePera reagent that Mn segregation occurs in hot rolled steels. As a result of this segregation, Mn can combine with $\mathrm{S}$ during the last stages of solidification giving rise to $\mathrm{MnS}$ inclusions. These inclusions have been reported to act as moderate to strong trapping sites which can trap hydrogen reversibly [16] or irreversibly [15] and thereby reduce the diffusion of hydrogen. Consequently, the centreline samples should exhibit a lower diffusion coefficient. However, the samples that were used in the permeation studies did not appear to show any pronounced segregation in terms of the presence of $\mathrm{MnS}$ inclusions. In view of the above, the results obtained here cannot be explained on the basis of concentration of $\mathrm{MnS}$ particles; rather they can be rationalised on the basis of the microstructure of the samples. As seen in Figures 2 (a), (b) and Table 3, both the edge and centreline samples of the standard Mn strip show non-uniform microstructures with a bimodal distribution of grains. However, the edge sample has a larger number of very fine grains and whereas the fraction of grains having a larger size is higher in the centreline samples, resulting in a lower mean free path for the edge sample as compared to the centreline sample. As shown in an earlier publication [12] for X70 steel, ferrite grain sizes smaller than $45 \mu \mathrm{m}$ can reduce the mobility of hydrogen by trapping at nodes and triple junctions; with the extent of this trapping increasing with decreasing grain size. Consequently, the large number of finer grains in the edge region could increase the trapping of hydrogen and thereby give rise to a lower diffusion coefficient. In addition, it can be expected that the edge region of the strip would contain a higher density of dislocations as compared to the centreline region, because the faster cooling rate during processing of the strip promotes transformation to ferrite at lower temperature with an increase in dislocation density, arising from the transformation volume change. Since dislocations act as reversible traps for hydrogen, the combined effect of a lower grain size and higher dislocation density of the edge region of the strip could result in the lower diffusivity of hydrogen.

Some banding of ferrite-pearlite grains parallel to the rolling direction of the strip was also observed in the centreline samples. Since the samples for permeability tests were obtained by cutting slices parallel to the rolling plane, this means that the banding was perpendicular to the direction of hydrogen entry and movement. The effective diffusivities of hydrogen in such specimens have been reported to be an order of magnitude lower than when hydrogen entry was along the direction of banding [49-50]. However, in this study the small amount of banding did 
not appear to have any significant effect in decreasing the diffusion of hydrogen in the centreline samples as compared to the non-banded edge samples.

\section{$\underline{\text { 4.2.2 Comparison of medium Mn strip edge and centreline }}$}

Comparison of the permeation transients of the two regions of the medium Mn strip (Figure 6 (b)) indicates that there is little difference in the form of the transients and therefore their hydrogen diffusivity values are similar (Table 4). Examination of the microstructures of the two regions revealed that the grain sizes were uniform and comparable, with the edge region showing only a marginally lower mean free path. Therefore, the similarity of the mean free paths in the ferrite phase for the two regions is consistent with the similarity of the permeation transients.

\subsubsection{Comparison of standard Mn and medium Mn strip}

The plot comparing the edge regions of the standard and medium Mn strips is shown in Figure 6 (c). The breakthrough time and lag time for the medium Mn edge sample were longer than for the standard Mn edge sample, indicating that trapping is more effective in the medium Mn strip. An examination of the microstructure of the edge regions of the two steels reveals that the standard Mn strip has a larger number of grains having a finer grain size and consequently a smaller mean free path in the ferrite phase. As discussed earlier, a finer grain size is expected to trap hydrogen and lower its mobility. In view of the grain size effect, the SME samples should have shown a lower diffusivity, i.e., longer breakthrough and lag times. However, the permeation results show the opposite.

Recent studies involving precipitate analysis of the two steels using scanning electron microscopy [51] have shown that the medium Mn steel exhibits a significantly larger number density of precipitates and inclusions. Most of these precipitates were found to be complex carbonitrides of $\mathrm{Ti}$ and $\mathrm{Nb}$ having an average diameter of $0.8 \pm 0.8 \mu \mathrm{m}$. The higher $\mathrm{Ti}, \mathrm{C}$ and $\mathrm{N}$ contents of the medium Mn X70 steel were reported to result in a significantly larger fraction of carbonitride precipitates. Fine precipitates of $\mathrm{TiC}, \mathrm{NbC}$ or complex carbonitrides of $\mathrm{Ti}$ and $\mathrm{Nb}$ have been found to act as strong irreversible traps [2, 18, 19]. Permeability studies in pipeline steels by Koh et al. [30] have also shown that diffusivity of hydrogen decreases as the density of 
precipitates increases. Therefore, the lower diffusivity of the medium Mn strip compared to the standard Mn strip can be attributed to the presence of these precipitates which trap hydrogen effectively and reduce its mobility. This is also consistent with the higher density of traps calculated for the medium Mn strip, as seen in Table 5.

The permeation transients of the centreline regions of the two steels also show a similar trend (Figure 6 (d)) with a slightly larger difference in the two strips compared to the edge region. Again the lower diffusivity of the medium Mn steel can be attributed to the presence of precipitates. In addition, the mobility of hydrogen in the MMC samples is further reduced by the contribution to trapping because of a slightly lower mean free path compared to the SMC samples (Table 3). Therefore, the permeation transients show a slightly greater difference, relative to those for the edge samples.

\subsubsection{Comparison of standard Mn transfer bar edge and centreline}

Figure 6 (e) shows the permeation plots for the edge and centreline regions of the X70 TB. This figure indicates that diffusion is faster in the centreline region of the TB than the edge region. This effect can be attributed to the coarse granular bainite microstructure formed from coarser prior austenite grains of TB centreline samples. In contrast, the edge region has a mixture of finer bainitic ferrite laths and quasi-polygonal ferrite. In addition to the bainitic ferrite grains being fine with a lower mean free path, the edge microstructure is expected to have a high density of dislocations which can also trap hydrogen and reduce its mobility. Therefore, the TBE samples exhibit a lower diffusivity compared to the TBC samples.

\section{$\underline{\text { 4.2.5 Comparison of standard Mn TB edge and normalised TB edge }}$}

The transient for the NTB sample is compared with the TBE sample in Figure 6 (f). Not only is the breakthrough time for the NTB shorter, the transient is also significantly steeper than the TBE sample, so that the steady state is attained in a shorter time. These observations suggest that the diffusion of hydrogen is very fast through the NTB microstructure due to the absence of features that can act as effective traps for hydrogen. This is clearly a consequence of the large polygonal ferrite grains of the normalised microstructure, which is reflected in its significantly larger mean free path (Table 3). In addition, the dislocation density is low due to the normalising treatment so 
that the trapping potential is minimized for this sample. In contrast, the TBE sample had fine bainitic ferrite structure, smaller grains of quasi-polygonal ferrite and a higher dislocation density. These factors combine to effectively trap hydrogen and reduce its mobility, giving rise to a longer breakthrough time and a less steep permeation transient.

\subsubsection{Comparison of normalised TB and hot rolled strip of the standard Mn steel}

Figure $6(\mathrm{~g})$ shows a comparison of the first transients obtained for the NTB and SME samples, both of which have a ferrite-pearlite microstructure. The normalised microstructure consists of coarse equiaxed grains with a relatively low dislocation density whereas the hot rolled strip has fine and somewhat elongated grains that are expected to have a higher dislocation density. Accordingly, the hardness value of $198 \pm 7 \mathrm{HV}$ for the hot rolled strip (Table 3) is significantly higher than for the normalised transfer bar $(142 \pm 9 \mathrm{HV})$. Relative to the NTB sample, there was a substantial increase in the breakthrough time and the time to attain a steady state for the SME sample, because the finer grains and the higher density of dislocations effectively trap hydrogen and significantly reduce its mobility, compared to the coarse equiaxed grains in the normalised microstructure.

\section{Conclusions}

The medium Mn strip showed the lowest diffusivity due to the combined effect of a fine grain size and a high density of $(\mathrm{Ti}, \mathrm{Nb}) \mathrm{C}, \mathrm{N}$ precipitates.

$>$ The normalised transfer bar showed the highest diffusivity due to its large ferrite grains and a very low dislocation density.

Similar grain sizes for the edge and centreline samples of medium Mn X70 strip resulted in exhibiting similar hydrogen diffusivities, whereas standard X70 edge samples showed lower diffusivities than the centreline samples due to the combination of finer grain size and a higher dislocation density. 
> The low dislocation density and coarser ferrite-pearlite structure of the normalised TB edge sample exhibited a significantly higher diffusivity than the SME sample despite the similarity of the microstructure.

$>$ The fine structure of bainitic ferrite and associated high dislocation densities of the TB edge sample resulted in a lower diffusivity than the granular bainite formed from coarser prior austenite grains of the TB centreline sample.

\section{Acknowledgements}

This study was conducted as part of Australian Research Council (ARC) Linkage Grant (LP0883546) with BlueScope Steel Ltd. (BSL) as the industrial partner. The authors would like to thank the ARC and BSL for their financial support. The authors would also like to thank BSL for providing the Hyperm Mod HM 403 unit for carrying out the permeability measurements.

\section{References}

1. Lee JY, Lee SM. Hydrogen trapping phenomena in metals with B.C.C. and F.C.C. crystals structures by the desorption thermal analysis technique. Surface and Coatings Technology 1986; 28: 301-14.

2. Pressouyre GM, Bernstein I. A Quantitative Analysis of Hydrogen Trapping. Metallurgical Transactions A 1978; 10: 1571-80.

3. Villalba E, Atrens A. SCC of commercial steels exposed to high hydrogen fugacity. Engineering Failure Analysis 2008; 15: 617-41.

4. Calder RD, Elleman TS, Verghese K. Grain boundary diffusion of tritium in 304- and 316stainless steels. Journal of Nuclear Materials 1973; 46: 46-52.

5. Kimura A, Birnbaum HK. Hydrogen induced grain boundary fracture in high purity nickel and its alloys-Enhanced hydrogen diffusion along grain boundaries. Acta Metallurgica 1988; 36: 75766.

6. Tsuru T, Latanision RM. Grain boundary transport of hydrogen in nickel. Scripta Metallurgica 1982; 16: 575-8.

7. Brass AM, Chanfreau A. Electrochemical permeation of hydrogen in high purity nickel at $100^{\circ}$ C. Scripta Metallurgica et Materialia 1990; 24: 499-504.

8. Choo WY, Lee JY, Cho CG. Effect of Grain Size. Materials science 1981; 16: 1285-93. 
9. Wert CA. Trapping of hydrogen in metals. In: Alefeld G, Volkl J, editors. Hydrogen in metals II. Application-Oriented Properties: Springer-Verlag; 1978, p. 305-330.

10. Yao J, Cahoon JR. Theoretical Modeling of Grain Boundary Diffusion of Hydrogen and its Effect on Permeation Curves. Acta Metallurgica et Materialia 1991; 39: 119-26.

11. Ichimura M, Sasajima Y, Imabayashi M. Grain Boundary Effect on Diffusion of Hydrogen in Pure Aluminum. in Materials transactions JIM 1991; 32: 1109-14.

12. Yazdipour N, Haq AJ, Muzaka K, Pereloma EV. 2D modelling of the effect of grain size on hydrogen diffusion in X70 steel. Computational Materials Science 2012; 56: 49-57.

13. Huang F, Liu J, Deng ZJ, Cheng JH, Lu ZH, Li XG. Effect of microstructure and inclusions on hydrogen induced cracking susceptibility and hydrogen trapping efficiency of X120 pipeline steel. Materials Science and Engineering A 2010; 527: 6997-7001.

14. Xue HB, Cheng YF. Characterization of inclusions of X80 pipeline steel and its correlation with hydrogen-induced cracking. Corrosion Science 2011; 53: 1201-8.

15. Lee SM, Lee JY. The effect of the interface character of TiC particles on hydrogen trapping in steel. Acta Metallurgica 1987; 35: 2695-700.

16. Garet M, Brass AM, Haut C, Guttierez-Solana F. Hydrogen trapping on non metallic inclusions in Cr-Mo low alloy steels. Corrosion Science 1998; 40: 1073-86.

17. Stevens MF, Bernstein IM. Metall Trans A 1989; 20A: 909-19.

18. Takahashi I, Matsumoto Y, Tanaka T. in Proc. JIMIS-2. 1979. Minakami, Tokyo, Japan.

19. Valentini R, Solina A, Matera S, De Gregorio P. Influence of Titanium and Carbon Contents on the Hydrogen Trapping of Microalloyed Steels. Metallurgical and materials Transactions A 1996; 27: 3773-80.

20. Wei FG, Tsuzaki K. Quantitative Analysis on Hydrogen Trapping of TiC Particles in Steel. Metallurgical and Materials Transactions A 2006; 37: 331-53.

21. Wei FG, Hara T, Tsuzaki K. Nano-Precipitates Design with Hydrogen Trapping Character in High Strength Steels. In: Somerday B, Sofronis P, Jones R, editors. Effects of Hydrogen on Materials, Proceedings of the International Hydrogen Conference, Wyoming, USA; 2008, p 448455.

22. Wei FG, Tsuzaki K. Hydrogen Trapping Character of Nano-Sized NBC Precipitates in Tempered Martensite. In: Somerday B, Sofronis P, Jones R, editors. Effects of Hydrogen on Materials, Proceedings of the International Hydrogen Conference, Wyoming, USA; 2008, p 456463.

23. Yamasaki S, Takahashi T. Evaluation method of delayed fracture property of high strength steels. Tetsu-to-Hagane 1997; 83: 454-9. 
24. Yuan X. Precipitates and hydrogen permeation behavior in ultra-low carbon steel. Materials Science and Engineering: A 2007; 452-453: 116-20.

25. Andenna C, Torella R. A Study of Hydrogen Permeation on API X65 TMCP Steel Under Stress Conditions. In: Turnbull A, editor. Hydrogen transport and cracking in metals. Proceedings of a conference, Teddington UK;1995, p. 240-252.

26. Contreras A, Albiter A, Salazar M, Pérez R. Slow strain rate corrosion and fracture characteristics of X-52 and X-70 pipeline steels. Materials Science and Engineering: A 2005; 407: 45-52.

27. Dong CF, Li XG, Liu ZY, Zhang YR. Hydrogen-induced cracking and healing behaviour of X70 steel. Journal of Alloys and Compounds 2009; 484: 966-72.

28. Dong CF, Liu ZY, Li XG, Cheng YF. Effects of hydrogen-charging on the susceptibility of X100 pipeline steel to hydrogen-induced cracking. International Journal of Hydrogen Energy 2009; 34: 9879-84.

29. Kim WK, Koh SU, Yang BY, Kim KY. Effect of environmental and metallurgical factors on hydrogen induced cracking of HSLA steels. Corrosion Science 2008; 50: 3336-42.

30. Koh SU, Kim JS, Yang BY, Kim KY. Effect of Line Pipe Steel Microstructure on Susceptibility to Sulfide Stress Cracking. Corrosion Science 2004; 60: 244-54.

31. Park GT, Koh SU, Jung HG, Kim KY. Effect of microstructure on the hydrogen trapping efficiency and hydrogen induced cracking of linepipe steel. Corrosion Science 2008; 50: 186571.

32. Ramírez E, González-Rodriguez JG, Torres-Islas A, Serna S, Campillo B, DominguezPatiño G, Juárez-Islas JA. Effect of microstructure on the sulphide stress cracking susceptibility of a high strength pipeline steel. Corrosion Science 2008; 50: 3534-41.

33. Scoppio L, Barteri M. Methods of Hydrogen Uptake Measurements by Electrochemical Permeation Test on Low Alloy Steels. In: Turnbull A, editor. Hydrogen transport and cracking in metals. Proceedings of a conference, Teddington UK;1995, p. 204-215.

34. Serna S, Martínez H, López SY, González-Rodríguez JG, Albarrán JL. Electrochemical technique applied to evaluate the hydrogen permeability in microalloyed steels. International Journal of Hydrogen Energy 2005; 30: 1333-1338.

35. Skjellerudsveen M, Akselsen OM, Olden V, Johnsen R, Smirnova A. Effect of Microstructure and Temperature on Hydrogen Diffusion and Trpping in X70 Grade Pipeline Steel and Its Weldments. in Proceedings of the 2010 EUROCORR Conference, Moscow, Russia; 2010.

36. Williams JG. Advances in Steels for High Strength ERW Linepipe Applications in Australia. Materials Forum 2007; 31: 1-10. 
37. Devanathan MAV, Stachurski Z. The Adsorption and diffusion of electrolytic hydrogen in palladium. The royal society of london A 1962; 270: 90-102.

38. Iino M. Analysis of Irreversible Hydrogen Trapping. Acta Metallurgica 1982; 30: 377-83.

39. Turnbull A, Carroll MW. The Effect of Temperature and $\mathrm{H}_{2} \mathrm{~S}$ Concentration on Hydrogen Diffusion and Trapping in a 13\% Chromium Martensitic Stainless Steel in Acidified NaCl. Corrosion Science 1990; 30: 667-79.

40. Kiuchi K, McLellan RB. The Solubility and Diffusivity of Hydrogen in Well-Anealed and Deformed Iron. Acta Metallurgica et Materialia 1983; 31: 961-84.

41. Dunne DP. Ferrite Morphology and Residual Phases in Continuously Cooled low Carbon Steels. Materials Forum 1999; 23: 63-76.

42. Desforges CD, Duckworth WE, Ryan TFJN, Manganese in ferrous metallurgy: The Manganese Centre, Paris 1977.

43. Manolatos P, Jerome M, Thual CD, Coze JL. The Electrochemical Permeation of Hydrogen in Steels Without Palladium Coating. Part I: Interpretation Difficulties. Corrosion Science 1995; 37: $1773-83$.

44. Beck B, Bockris JO, McBreen J, Nanis L. Proceedings of the Royal Society of London A 1966; 290: 220 .

45. P.Amiot AB, G.Pinard-Legry. Contribution a I'etude du cloquage des a\&r pour constructions soudees. presentee a Deuxieme Congres International. L'hydrogene dans les metaux. Paris, 3E8. 1977.

46. Bruzzoni P, Garavaglia R. Anodic Iron Oxide Films and Their Effect on The Hydrogen Permeation Through Steel. Corrosion Science 1992; 33: 1797-807.

47. Charbonnier JC, Margot-Marette H, Brass AM, MAucoutier M. Sulfide Stress Cracking of High Strength Modified Cr-Mo Steels. Metallurgical Transactions A 1985; 16 A: 935-44.

48. Pérez Escobar D, Miñambres C, Duprez L, Verbeken K, Verhaege M. Internal and surface damage of multiphase steels and pure iron after electrochemical hydrogen charging. Corrosion Science 2011; 53: 3166-76.

49. Lee HL, Chan SLI. Hydrogen embrittlement of AISI 4130 steel with an alternate ferrite/pearlite banded structure. Materials Science and Engineering A 1991; 142: 193-201.

50. Tau L, Chan SLI. Effects of ferrite/pearlite alignment on the hydrogen permeation in a AISI 4130 steel. Materials Letters 1996; 29: 143-7.

51. Hejazi D, Haq AJ, Yazdipour N, Dunne DP, Calka A, Barbaro F, Pereloma EV. Effect of Manganese content and microstructure on the susceptibility of pipeline steel to hydrogen cracking. Materials Science and Engineering A 2012; 551:40-49. 


\section{LIST OF TABLES}

Table 1: Summary of permeation parameters for pipeline steels in literature.

Table 2: Chemical compositions of the steels investigated (wt. \%).

Table 3: Sample notation, mean free path in ferrite and hardness.

Table 4: Diffusion coefficients calculated by different methods.

Table 5: Trap density, flux, permeability and solubility. 


\section{FIGURE CAPTIONS}

Figure 1: Schematic showing the location of edge and centreline samples of the strip/transfer bar.

Figure 2: Optical micrographs of the strip samples (a) standard Mn edge; (b) standard Mn centerline; (c) medium Mn edge; and (d) medium Mn centreline.

Figure 3: Optical micrographs of transfer bar samples (a) edge; (b) its magnified image; (c) centerline; and (d) normalised transfer bar. 1 and 2 indicate regions of different morphologies: bainitic ferrite and polygonal and/or quasi-polygonal ferrite, respectively.

Figure 4: Typical permeation curves for samples examined in this study. (a) complete plot of two successive permeation cycles for normalised transfer bar sample; and (b) a plot showing the first and second transients for the medium Mn edge sample with the second transient (dashed line) superimposed on the first transient line.

Figure 5: Variation in hardness and diffusion coefficient with mean free path for samples having similar ferrite-pearlite structure and composition.

Figure 6: Comparison of the first permeation transients for (a) standard Mn strip edge and centreline samples; (b) medium Mn strip edge and centreline; (c) standard and medium Mn strip edge; (d) standard and medium Mn strip centreline; (e) transfer bar edge and centreline; (f) transfer bar edge and normalised transfer bar edge; and (g) normalized transfer bar and hot rolled strip of standard Mn steel. 
Table 1: Summary of permeation parameters for pipeline steel in literature.

\begin{tabular}{|c|c|c|c|c|c|c|c|c|c|c|c|}
\hline Publication & Steel & Solution & $\begin{array}{l}\text { Coat- } \\
\text { ing }\end{array}$ & \multicolumn{3}{|c|}{ Microstructure } & Method & $\begin{array}{c}D\left(10^{-10}\right. \\
\left.m^{2} s^{-1}\right)\end{array}$ & 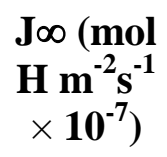 & $\begin{array}{c}\text { JœL (mol } \\
\mathbf{H ~ m}^{-1} \mathbf{s}^{-1} \times \\
\left.\mathbf{1 0}^{-10}\right)\end{array}$ & $\begin{array}{c}\mathbf{C}_{\text {app }}(\mathrm{mol} \\
\left.\mathbf{H ~ m}^{-3}\right)\end{array}$ \\
\hline$[27]$ & $\mathrm{X} 70$ & \multirow{2}{*}{$\begin{array}{c}0.5 \mathrm{M} \mathrm{H}_{2} \mathrm{SO}_{4} \\
+ \\
250 \mathrm{mg} / 1 \\
\mathrm{NaAsO}_{2} \\
\end{array}$} & $\mathrm{Ni}$ & \multicolumn{3}{|l|}{$\mathrm{F}+\mathrm{AF}$} & Time lag & 0.263 & 9.85 & 7.6 & 28.8 \\
\hline$[28]$ & $\mathrm{X} 100$ & & & \multicolumn{3}{|l|}{$\mathrm{F}+\mathrm{B}$} & Time lag & 0.01 & 2.65 & 1.4 & 134 \\
\hline \multirow{5}{*}[31]{} & \multirow{5}{*}{ X65 } & \multirow{5}{*}{ NACE } & \multirow{5}{*}{$\mathrm{Pd}$} & & $\begin{array}{c}\text { DP/AF/ } \\
\mathrm{B}, \%\end{array}$ & $\mathrm{M} / \mathrm{A}, \%$ & \multirow{5}{*}{$\begin{array}{l}\text { Break- } \\
\text { through }\end{array}$} & \multirow{5}{*}{$4.05-9.4$} & \multirow{5}{*}{--} & \multirow{5}{*}{$0.8-1.4$} & \multirow{5}{*}{$13-28$} \\
\hline & & & & $\mathrm{F}+\mathrm{AF}$ & 8.12 & 5.73 & & & & & \\
\hline & & & & $\mathrm{F}+\mathrm{B}$ & 9.38 & 4.45 & & & & & \\
\hline & & & & $\mathrm{F}+\mathrm{DP}$ & 3.75 & 1.28 & & & & & \\
\hline & & & & $\mathrm{F}+\mathrm{DP}$ & 3.93 & 0.88 & & & & & \\
\hline [29] & $\mathrm{X} 70$ & NACE & $\mathrm{Pd}$ & \multicolumn{3}{|c|}{$\mathrm{F}+\mathrm{DP}+\mathrm{AF}, \mathrm{F}+\mathrm{AF}+\mathrm{BF}$} & \multirow{2}{*}{$\begin{array}{l}\text { Break- } \\
\text { through }\end{array}$} & $0.5-4.3$ & -- & -- & -- \\
\hline [34] & X52 & NACE & $\mathrm{Pd}$ & $\mathrm{F}+\mathrm{P}, A$ & & & & $0.15-0.24$ & -- & -- & $\begin{array}{c}2.6 \times 10^{5} \\
27.41\end{array}$ \\
\hline$[33]^{*}$ & X65 & $0.1 \mathrm{~N} \mathrm{NAOH}$ & -- & Q\&T & & & $\begin{array}{c}\text { Time } \\
\text { lag }\end{array}$ & $0.9-0.96$ & -- & -- & -- \\
\hline \multirow{2}{*}[25]{$^{* *}$} & \multirow{2}{*}{ X65 } & \multirow{2}{*}{ NACE } & \multirow{2}{*}{--} & \multicolumn{3}{|c|}{$\begin{array}{l}\mathrm{F}+\mathrm{P} \\
\mathrm{B}+\mathrm{M} / \mathrm{A}\end{array}$} & $\begin{array}{l}\text { Break- } \\
\text { through }\end{array}$ & $\begin{array}{l}2.4 \\
1.1 \\
\end{array}$ & -- & -- & $\begin{array}{r}5.7 \\
20.1 \\
\end{array}$ \\
\hline & & & & \multicolumn{3}{|c|}{$\begin{array}{l}\mathrm{F}+\mathrm{P} \\
\mathrm{B}+\mathrm{MA}\end{array}$} & $\begin{array}{c}\text { Time } \\
\text { lag }\end{array}$ & $\begin{array}{l}2.5 \\
1.2 \\
\end{array}$ & -- & -- & $\begin{array}{r}5.5 \\
15.6 \\
\end{array}$ \\
\hline [30] & API & NACE & $\mathrm{Pd}$ & \multicolumn{3}{|c|}{$\mathrm{F}+\mathrm{P}, \mathrm{F}+\mathrm{B}, \mathrm{F}+\mathrm{AF}$} & & $3.5-9.5$ & -- & -- & -- \\
\hline$[14]$ & X80 & $0.5 \mathrm{M} \mathrm{H}_{2} \mathrm{SO}_{4}$ & $\mathrm{Pd}$ & \multicolumn{3}{|c|}{$\mathrm{F}+\mathrm{BF}+\mathrm{M} / \mathrm{A}$} & \multirow{2}{*}{$\begin{array}{l}\text { Time } \\
\text { lag }\end{array}$} & 0.2 & -- & 5.2 & 26 \\
\hline [35] & $\mathrm{X} 70$ & $0.1 \mathrm{~N} \mathrm{NAOH}$ & $\mathrm{Pd}$ & \multicolumn{3}{|c|}{$\mathrm{F}+\mathrm{P}+\mathrm{M}$} & & $0.73-0.79$ & -- & -- & -- \\
\hline
\end{tabular}

F - Ferrite, AF - Acicular Ferrite, B - Bainite, DP - Degenerated Pearlite, M/A - Martensite/Austenite, P - Pearlite, BF - Bainitic ferrite, GB - Granular Bainite, Q\&T - Quenched and tempered * For 1mm thick samples ** For Zero stress 
Table 2: Chemical compositions of the steels investigated (wt. \%).

\begin{tabular}{|c|c|c|c|c|c|c|c|c|c|c|c|c|c|c|c|}
\hline Steel & $\mathbf{C}$ & $\mathbf{P}$ & $\mathbf{M n}$ & $\mathbf{S i}$ & $\mathbf{N i}$ & $\mathbf{C r}$ & $\mathbf{M o}$ & $\mathbf{C u}$ & $\mathbf{A l}$ & $\mathbf{N b}$ & $\mathbf{T i}$ & $\mathbf{V}$ & $\mathbf{S}$ & $\mathbf{C a}$ & $\mathbf{N}$ \\
\hline $\mathbf{X 7 0}$ & 0.074 & 0.012 & 1.14 & 0.22 & 0.024 & 0.029 & 0.1 & 0.023 & 0.019 & 0.06 & 0.02 & 0.002 & 0.002 & 0.0002 & 0.0041 \\
\hline MX70 & 0.085 & 0.01 & 0.5 & 0.19 & 0.018 & 0.26 & 0.11 & 0.011 & 0.04 & 0.059 & 0.035 & 0.003 & 0.002 & 0.001 & 0.0054 \\
\hline
\end{tabular}


Table 3: Sample notation, mean free path in ferrite and hardness.

\begin{tabular}{|l|c|c|c|}
\hline \multicolumn{1}{|c|}{ Sample } & Notation & $\begin{array}{c}\text { Mean free path } \\
(\mu \mathbf{m})\end{array}$ & $\begin{array}{c}\text { Average Hardness } \\
(\mathbf{H V})\end{array}$ \\
\hline X70 Edge & SME & $2.97 \pm 0.12$ & $198 \pm 7$ \\
\hline X70 Centreline & SMC & $4.52 \pm 0.18$ & $187 \pm 8$ \\
\hline MX70 Edge & MME & $3.96 \pm 0.37$ & $187 \pm 6$ \\
\hline MX70 Centreline & MMC & $4.05 \pm 0.38$ & $170 \pm 6$ \\
\hline X70 TB Edge & TBE & $4.26 \pm 0.33$ & $189 \pm 3$ \\
\hline X70 TB Centreline & TBC & $5.28 \pm 0.34$ & $142 \pm 9$ \\
\hline Normalised TB & NTB & $8.93 \pm 0.89$ & 186 \\
\hline
\end{tabular}


Table 4: Diffusion coefficients calculated by different methods.

\begin{tabular}{|c|c|c|c|c|c|c|}
\hline \multirow{2}{*}{ Sample } & \multicolumn{2}{|c|}{$D_{t b}\left(\times 10^{-10} \mathrm{~m}^{2} \mathrm{~s}^{-1}\right)$} & \multicolumn{2}{|c|}{$\mathrm{D}_{\mathrm{T}}\left(\times 10^{-10} \mathrm{~m}^{2} \mathrm{~s}^{-1}\right)$} & \multirow{2}{*}{$\begin{array}{c}D_{\mathrm{t} 0}^{\text {rise }} \\
\left(\times 10^{-10} \mathrm{~m}^{2} \mathrm{~s}^{-1}\right)\end{array}$} & \multirow{2}{*}{$\begin{array}{c}D_{t 0}^{\text {decay }} \\
\left(\times 10^{-11} \mathrm{~m}^{2} \mathrm{~s}^{-1}\right)\end{array}$} \\
\hline & First & Second & First & Second & & \\
\hline SME & $2.29 \pm 0.05$ & $4.09 \pm 1.5$ & $1.97 \pm 0.09$ & $1.77 \pm 0.06$ & $2.0 \pm 0.09$ & $5.90 \pm 0.2$ \\
\hline SMC & $3.02 \pm 0.07$ & $3.71 \pm 0.7$ & $2.25 \pm 0.19$ & $2.06 \pm 0.17$ & $2.14 \pm 0.15$ & $5.62 \pm 0.8$ \\
\hline MME & $1.88 \pm 0.19$ & $3.00 \pm 0.44$ & $1.70 \pm 0.04$ & $1.57 \pm 0.03$ & $1.67 \pm 0.07$ & $3.88 \pm 0.5$ \\
\hline MMC & $2.10 \pm 0.21$ & $2.54 \pm 0.61$ & $1.71 \pm 0.1$ & $1.52 \pm 0.11$ & $1.59 \pm 0.14$ & $4.82 \pm 0.5$ \\
\hline TBE & $3.70 \pm 0.02$ & $4.58 \pm 0.01$ & $2.10 \pm 0.19$ & $1.33 \pm 0.31$ & $1.68 \pm 0.4$ & $3.84 \pm 0.8$ \\
\hline TBC & $4.87 \pm 0.74$ & $5.4 \pm 0.63$ & $3.05 \pm 0.17$ & $2.15 \pm 0.30$ & $2.8 \pm 0.19$ & $6.04 \pm 0.7$ \\
\hline NTB & $5.66 \pm 0.23$ & $7.46 \pm 0.45$ & $4.01 \pm 0.02$ & $3.82 \pm 0.13$ & $3.62 \pm 0.58$ & $7.87 \pm 1.1$ \\
\hline
\end{tabular}


Table 5: Trap density, flux, permeability and solubility.

\begin{tabular}{|c|c|c|c|c|}
\hline Sample & $\mathrm{N}_{\mathrm{T}}\left(\times 10^{18} \mathrm{~m}^{-3}\right)$ & $\begin{array}{l}\text { Flux } \mathrm{J} \infty\left(\times 10^{-7}\right. \\
\left.\operatorname{mol} \mathbf{H ~ m}^{-2} \mathrm{~s}^{-1}\right)\end{array}$ & $\begin{array}{c}\text { Permeability J } \infty \mathrm{L}(\times \\
\left.\mathbf{1 0}^{-10} \mathrm{~mol} \mathrm{H} \mathrm{m}^{-1} \mathrm{~s}^{-1}\right)\end{array}$ & $\begin{array}{l}\mathrm{C}_{\text {app }}\left(\times \mathbf{1 0}^{-1}\right. \\
\left.\mathrm{mol} \mathrm{H} \mathrm{m}^{-3}\right)\end{array}$ \\
\hline SME & $2.68 \pm 0.12$ & $1.54 \pm 0.26$ & $1.66 \pm 0.25$ & $8.40 \pm 0.93$ \\
\hline SMC & $2.37 \pm 0.21$ & $1.92 \pm 0.22$ & $1.65 \pm 0.23$ & $7.38 \pm 0.56$ \\
\hline MME & $3.12 \pm 0.08$ & $1.82 \pm 0.26$ & $1.95 \pm 0.25$ & $11.5 \pm 1.5$ \\
\hline MMC & $3.10 \pm 0.18$ & $1.58 \pm 0.30$ & $1.55 \pm 0.35$ & $9.02 \pm 1.5$ \\
\hline $\mathrm{TBE}$ & $2.51 \pm 0.23$ & $1.60 \pm 0.06$ & $1.67 \pm 0.16$ & $8.02 \pm 1.5$ \\
\hline $\mathrm{TBC}$ & $1.70 \pm 0.1$ & $2.22 \pm 0.26$ & $2.34 \pm 0.20$ & $7.69 \pm 0.91$ \\
\hline NTB & $1.28 \pm 0.01$ & $3.43 \pm 0.26$ & $2.42 \pm 0.03$ & $6.03 \pm 0.11$ \\
\hline
\end{tabular}


Click here to download high resolution image

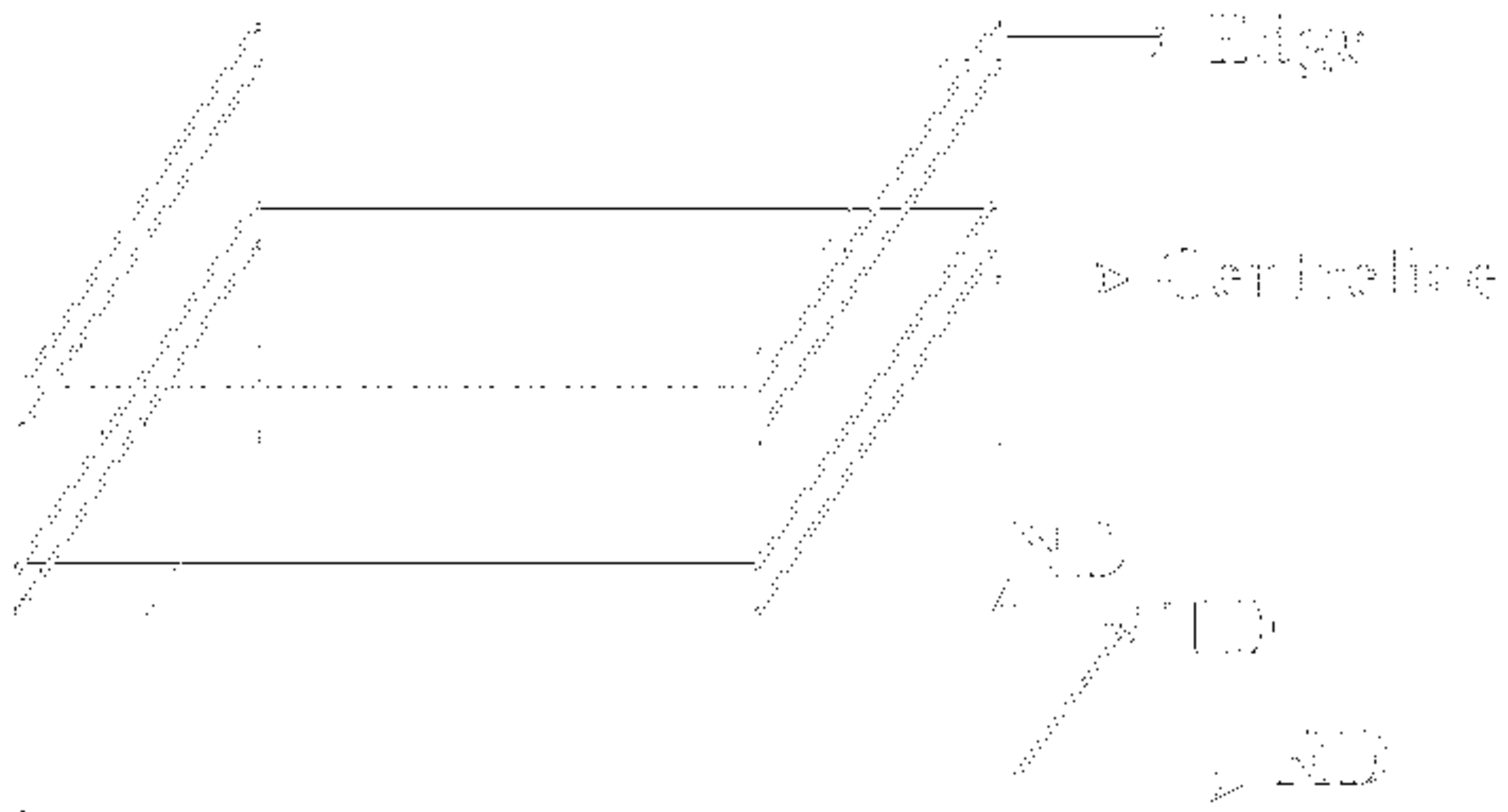


Click here to download high resolution image

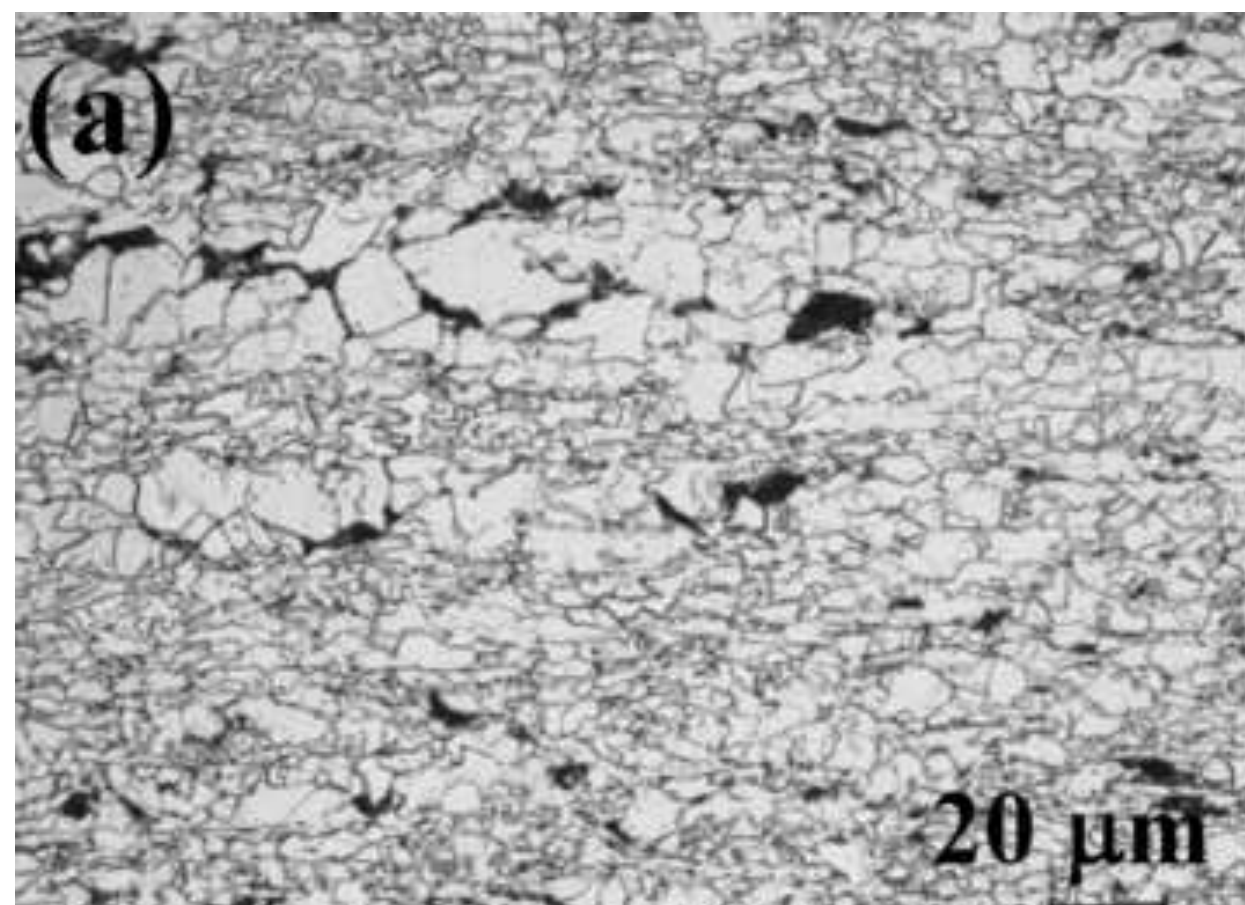

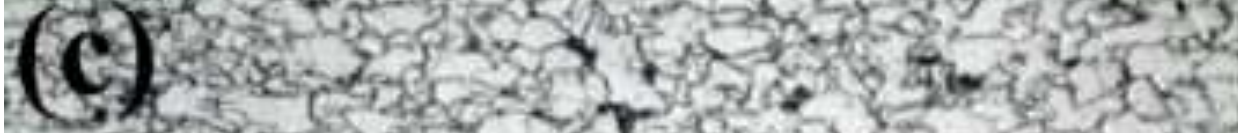

(d) 300 , s?

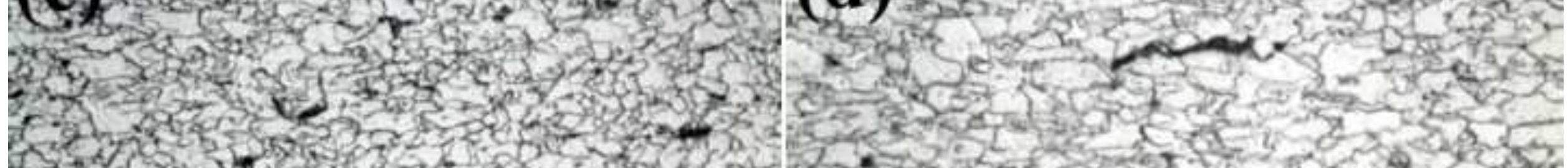

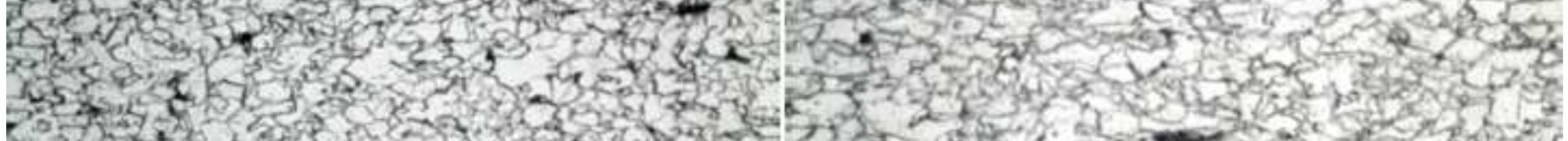

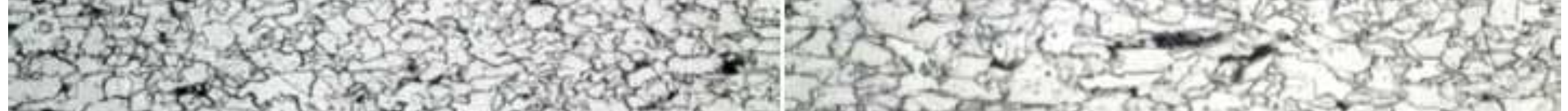

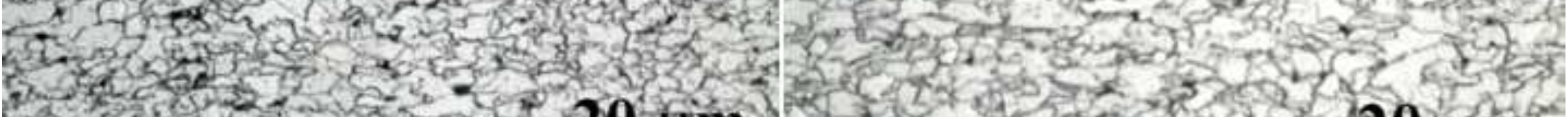

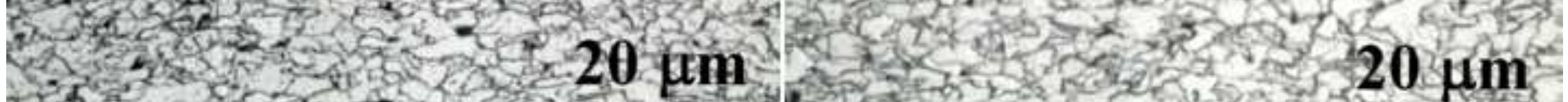

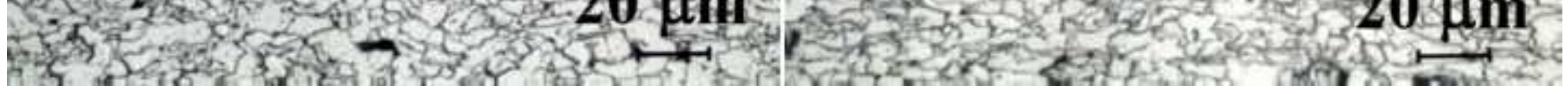


Click here to download high resolution image

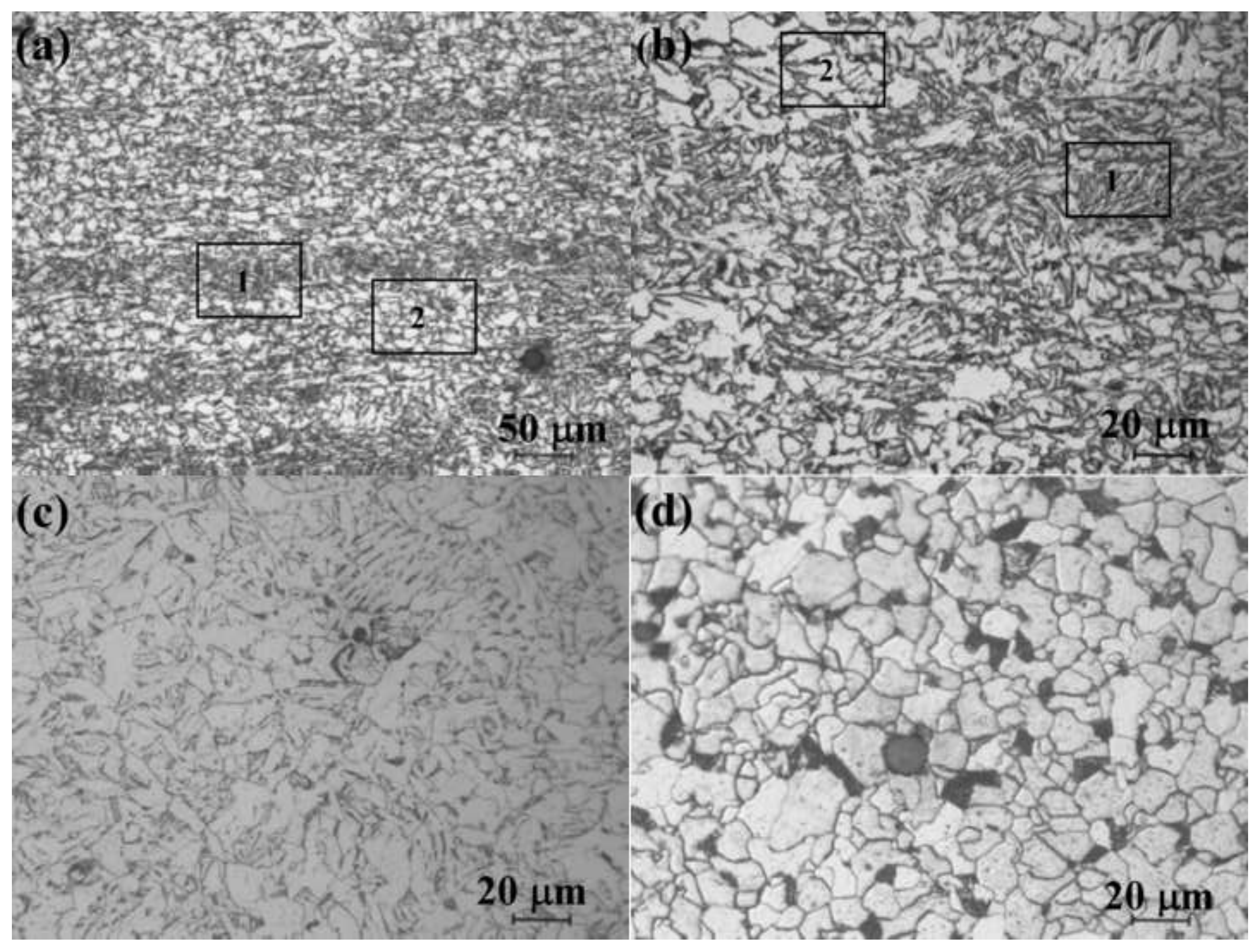


Click here to download high resolution image

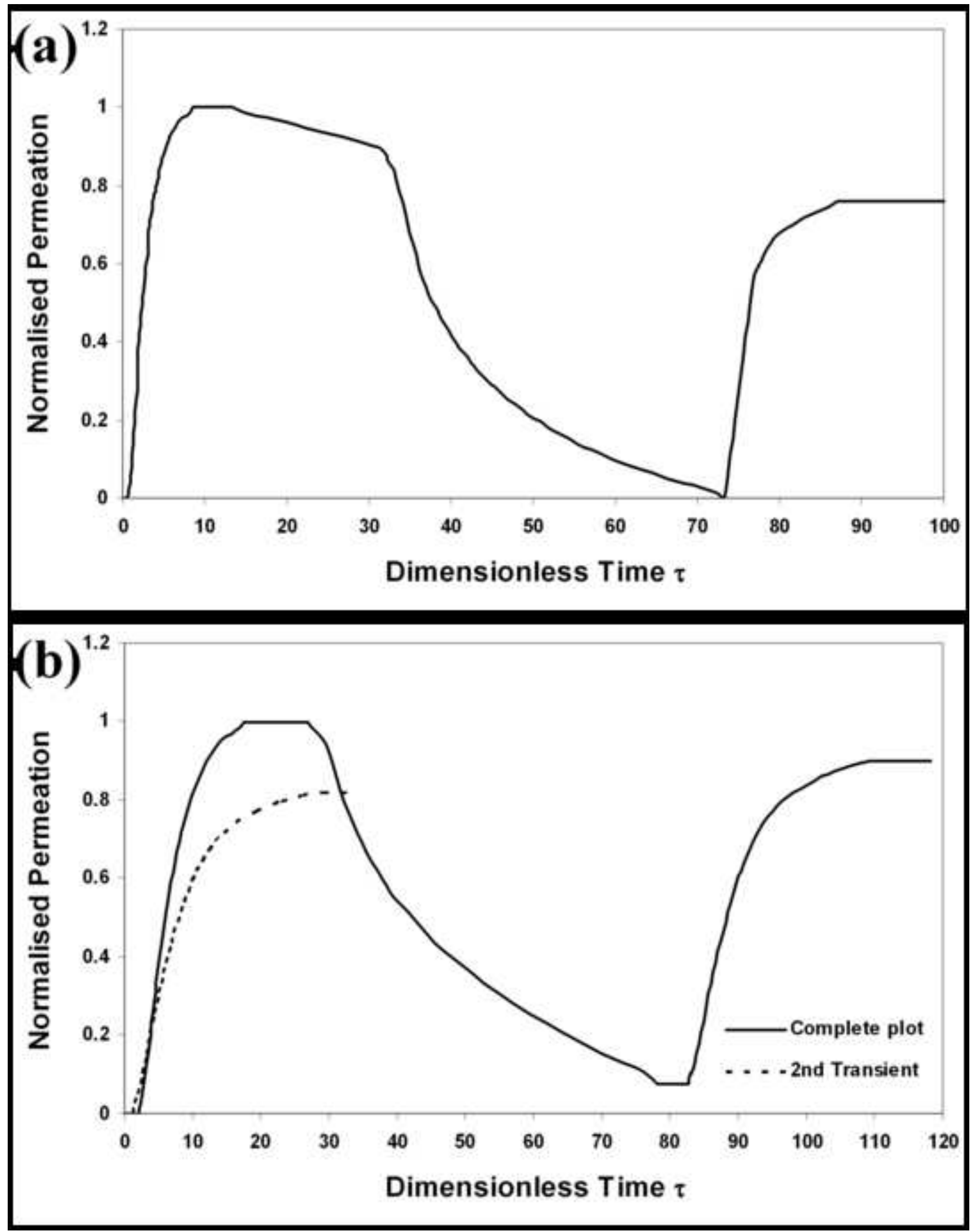




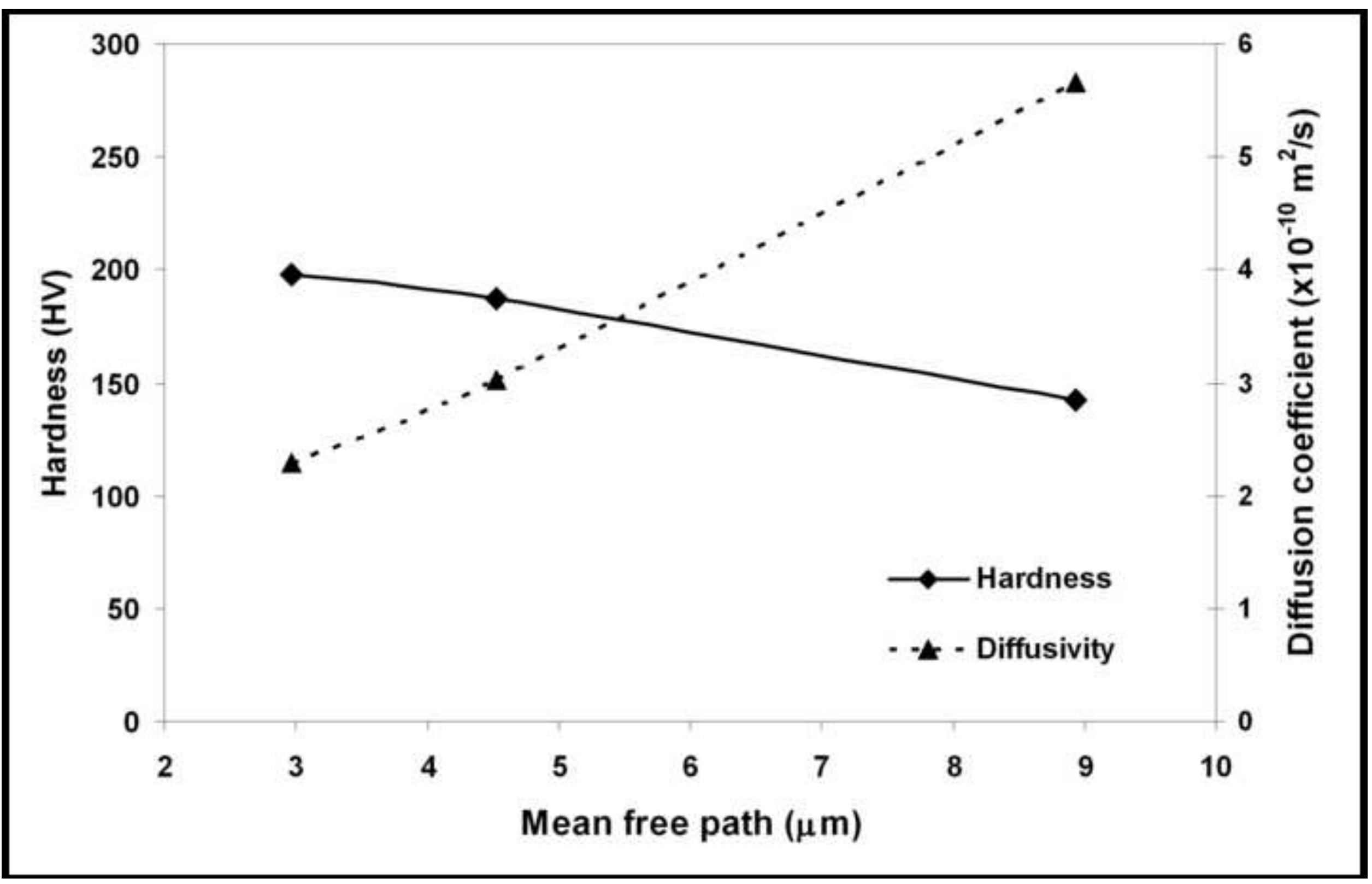


Click here to download high resolution image
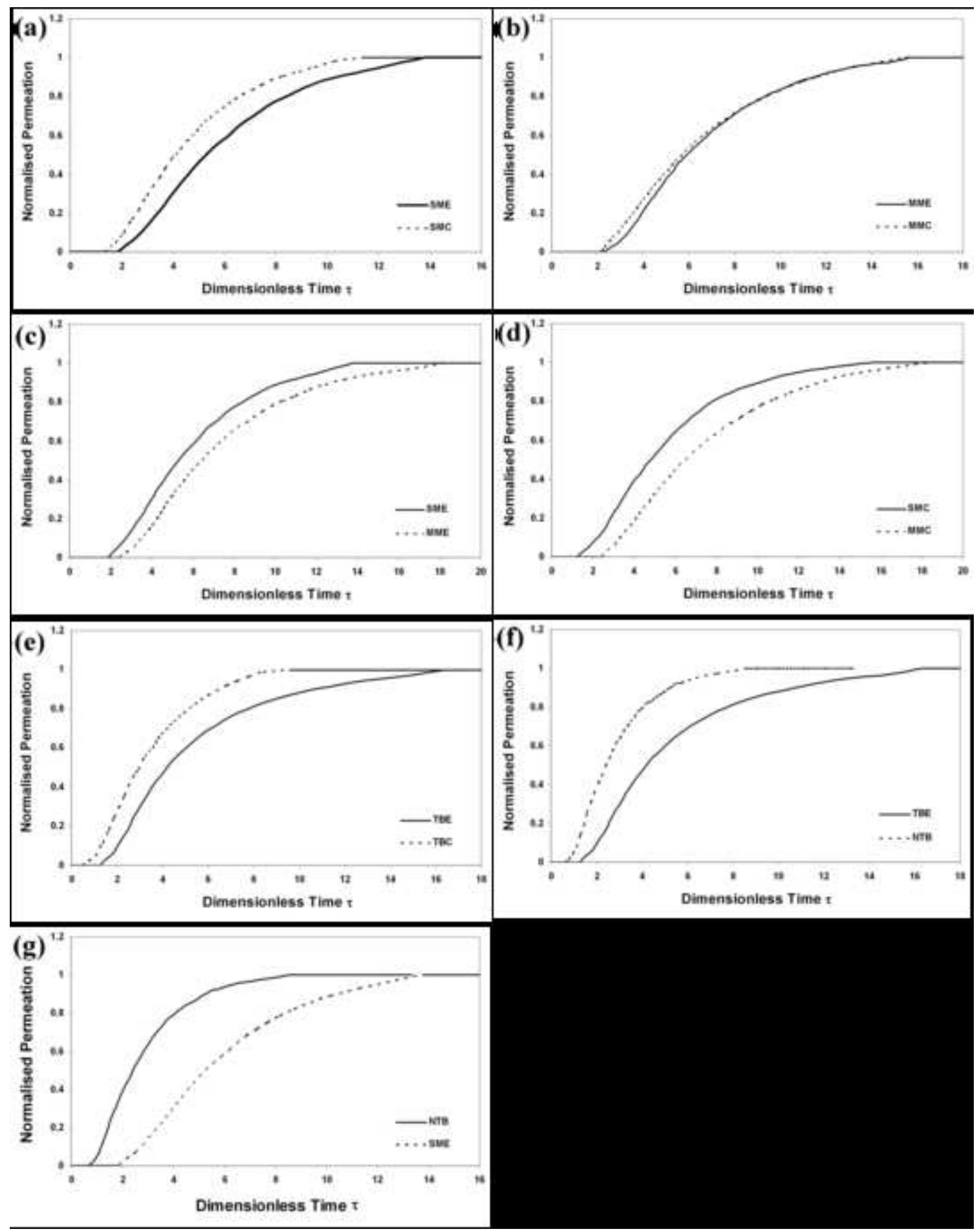